\title{
"Borges não acreditava na perfeição": entrevista com Daniel Balderston
}

Por Gisela Bergonzoni ${ }^{1}$

\section{DANIEL BALDERSTON É UM DOS MAIS RECONHECIDOS ESPECIALISTAS DA OBRA DO ESCRITOR ARGENTINO} JORGE LUIS BORGES. Professor do departamento de línguas e literaturas hispânicas da University of Pittsburgh, nos Estados Unidos, é diretor do Borges Center, que abriga em seu site ${ }^{2}$ um extenso material sobre a obra do autor e sua fortuna crítica. O trabalho de Balderston impactou os estudos da obra de Borges sob diferentes perspectivas teóricas, das pesquisas de suas fontes históricas até os estudos de gênero. Entre seus livros, destacam-se Out of context: Historical Reference and the Representation of Reality in Borges (1993), Borges, Realidad $y$ simulacros (2000) e Innumerables relaciones: cómo leer con Borges (2010). Nos últimos anos, Balderston tem se dedicado a uma tarefa de grande relevância para os estudos hispânicos contemporâneos: a crítica genética dos manuscritos de Borges, que estão espalhados por países diferentes - Estados Unidos, Argentina, Uruguai, Espanha, Suíça - em bibliotecas e coleções particulares. Grande parte dessa pesquisa está reunida no livro How Borges Wrote (University of Virginia Press, 2018), que Balderston considera seu maior feito nos quarenta anos em que passou destrinchando os escritos do argentino. Trata-se de um estudo incontornável sobre a gênese da obra borgeana: há reproduções facsimilares até então inéditas dos manuscritos de Borges e análises finas de suas anotações, de seus esboços e planos de trabalho, de cadernos preparatórios para cursos, de variantes e de cópias manuscritas de ensaios e contos. Nesta entrevista, concedida à Manuscrítica por videoconferência, Balderston falou sobre a busca detetivesca pelos manuscritos de Borges - digna talvez de um conto que o próprio autor argentino teria escrito -, sobre o árduo processo de composição de How Borges Wrote e sobre o status atual das pesquisas genéticas no mundo anglo-saxão. O livro foi publicado na França em 2019, sob o título La Méthode Borges, com tradução de Sophie Campbell (Presses Universitaires de Vincennes) e deverá ser lançado ainda este ano na Argentina, em uma versão ampliada, como El método Borges, com tradução de Ernesto Montequin (Ampersand).

Manuscrítica (M): Você foi um crítico e comentador da obra de Borges bem antes de estudar seus manuscritos. Seu trabalho sobre a referencialidade histórica em Borges, juntamente com a leitura de outros críticos (como Ricardo Piglia e Beatriz Sarlo) foi relevante para desfazer a imagem do intelectual alienado, encerrado em um mundo fantasioso. A pesquisa genética dos manuscritos, que é mais recente na sua carreira, é uma nova guinada crítica?

Daniel Balderston (DB): Desde minha tese de doutorado sobre Borges e Robert Louis Stevenson, que defendi

\footnotetext{
${ }^{1}$ Pesquisadora de pós-doutorado da Universidade Estadual de Campinas, com bolsa do programa CAPES-Print. O presente trabalho foi realizado com apoio da Coordenação de Aperfeiçoamento de Pessoal de Nível Superior - Brasil (CAPES) Processo 88887.571578/2020-00.

${ }^{2}$ https://www.borges.pitt.edu/
} 
em 1981, sempre voltava a estudar Borges por diferentes ângulos. Quando estava interessado na relação entre ficção e história, durante o boom dos estudos culturais, publiquei Out of context (1993). Já Borges, Realidad y simulacros (2000) é resultado de minha incursão pelos estudos de gênero e sexualidade. O tema da leitura surge com força em Innumerables relaciones: cómo leer con Borges (2010). Mas não sabia que iria um dia trabalhar com os manuscritos de Borges. Comecei a fazer uso das técnicas de estudos genéticos quando escrevi em 1996 um ensaio para a edição crítica de El beso de la mujer araña, de Manuel Puig, para a coleção Archivos (2002). Por volta de 1997, trabalhei com manuscritos de Juan Carlos Onetti, na Espanha, porque fui responsável pela edição de suas novelas (Novelas cortas, Centre de Recherches Latino-Américaines-Archivos, 2009). Mais tarde, foi a vez de investigar as traduções manuscritas de poesia de língua inglesa feitas por Juan José Saer. Só por volta de 2008 comecei a me perguntar: estou trabalhando com crítica genética, estudando autores que têm arquivos. Como fazer com um autor que estudo frequentemente, mas que não tem um arquivo, ou melhor, cujo arquivo precisa ser inventado?

M: O fato de os manuscritos de Borges estarem espalhados em bibliotecas de países diferentes e, além disso, de boa parte deles estar nas mãos de colecionadores privados, certamente prejudica a pesquisa, como você já assinalou diversas vezes. Em 2012, em um artigo para a Cuadernos Lirico ${ }^{3}$, escreveu que o material era escasso. Daquele momento até o imenso trabalho apresentado em How Borges Wrote, no qual você afirma ter consultado mais da metade dos manuscritos de Borges existentes, o que mudou? Como foi a experiência borgeana de compilar papéis perdidos?

DB: Quando comecei a procurar os manuscritos de Borges, por volta de 2010, de fato, tinha acesso a pouco material. Fui convidado a fazer uma palestra na National University of Ireland e queria falar sobre a leitura de Borges da obra William Butler Yeats, a quem ele dedicou um curso. Descobri que uma livraria e antiquário em Delaware tinha uma edição de 1946 do livro Towards a Mythology: Studies in the Poetry of W.B. Yeats, de Peter Ure, em que havia anotações de Borges nas últimas quatro folhas. A livraria pôs o livro à venda na internet por 10.000 dólares, e, no anúncio, havia uma digitalização da primeira folha anotada por Borges, que era uma lista de temas. Nunca peguei o livro físico na mão, mas a partir dessas poucas anotações, fiz a palestra sobre Borges e Yeats. Quando voltei da Irlanda, escrevi ao livreiro dizendo que não tinha interesse em comprar o livro, mas que, como pesquisador, gostaria de saber o que havia nas outras páginas anotadas por Borges. O livreiro escaneou as quatro folhas e me mandou. Percebi que havia ali o começo de uma tradução poética, que Borges não chegou a terminar, do célebre poema Leda and the Swan (1933). Paralelamente, Laura Rosato e Germán Álvarez finalizavam a primeira versão de Borges: libros $y$ lecturas (2010), em que catalogaram os livros que Borges havia doado à Biblioteca Nacional argentina em 1973, quando renunciou ao cargo de diretor. Eles me convidaram em 2011 para uma palestra sobre as anotações de Borges nos livros que possuía. E então enveredei pela crítica genética de Borges.

\footnotetext{
${ }^{3}$ BALDERSTON, Daniel. "Los manuscritos de Borges: 'Imaginar una realidad más compleja que la declarada al lector", Cuadernos LIRICO, 7, 2012, consultado em 20 de abril de 2019. http://journals.openedition.org/lirico/505 ; DOI : 10.4000/lirico.505
} 
Quando eu já havia publicado vários artigos sobre o tema, Ricardo Piglia me falou de Víctor Aizenman, um antiquário em Buenos Aires que foi muito importante para minha pesquisa, pois me mostrou diversos manuscritos e me apontou onde poderia encontrar outros. Donald Yates, um dos primeiros tradutores de Borges nos Estados Unidos, também contribuiu para meus estudos. Era um grande colecionador. De 2012 em diante, eu visitava Yates todo verão na Califórnia para consultar os papéis de Borges. Após sua morte, em 2017, seu arquivo foi vendido à biblioteca de Michigan State University ${ }^{4}$. Foi quando percebi que ele não havia me mostrado tudo o que tinha (risos).

Entre os documentos de posse de Yates e de Aizenman, somados aos acervos de bibliotecas nos Estados Unidos, sobretudo as da University of Virginia e a New York State Library, tive acesso a em torno de 180 manuscritos, que usei em How Borges Wrote. Na época, calculava que isso correspondia a em torno de metade dos manuscritos das obras mais canônicas de Borges, escritas de 1930 até a segunda edição de Ficciones (1957). Atualmente, tenho acesso a mais de 300 manuscritos. Parte desse aumento tem a ver com a venda do arquivo de Yates à Michigan State University; parte se explica porque, após o lançamento de meu livro, alguns colecionadores quiseram me mostrar documentos que eu saberia interpretar. Agora os pesquisadores têm acesso a documentos do período mais tardio de Borges, como textos que estão em El Hacedor (1960) e os cadernos de anotações para as aulas e palestras que Borges deu entre 1949, quando perdeu o medo de falar em público, até a cegueira, em 1955. Esses cadernos vão ser muito importantes para o futuro dos estudos de Borges. Quando escrevia nesses cadernos, estava consciente de que iria perder a capacidade de ler. Para preparar seus cursos, tomava o cuidado de anotar as páginas das referências que usava, pois sabia que a mãe e os amigos o ajudariam a reencontrá-las no futuro. Donald Yates disse que a mãe de Borges conservava em seu quarto 43 cadernos. Desses 43 , sabemos da existência de 40. A maioria está conservada no Harry Ransom Center ${ }^{5}$, da University of Texas, e na Michigan State University. Há alguns cadernos na New York Public Library e na University of Virginia e temos um aqui na University of Pittsburgh, que contém os manuscritos do conto "La espera" (1950) e do ensaio "El escritor argentino y la tradición” (1951), que estudei em How Borges Wrote. Onze dos cadernos de Borges estão em arquivos privados e, no momento, inacessíveis aos pesquisadores - ao menos aos da minha equipe.

\section{M: Nos últimos anos, as pesquisas conduzidas pelo Borges Center contribuíram significativamente}

para novas leituras da obra borgeana. Que aspectos dessa crítica mais recente, suscitada pelo estudo genético, você observa?

DB: A revista que publicamos, Variaciones Borges, não é necessariamente sobre crítica genética, mas temos dedicado alguns números especiais ao assunto, como o 38, de outubro de 2014. O próximo número, 52, que deve sair em outubro de 2021, será uma contribuição importante para os estudos genéticos: terá em torno de vinte artigos sobre as anotações de Borges nesses cadernos de 1949 a 1955. Como o material é bastante heterogêneo, diferentes pesquisadores - de especialistas em sufismo até literatura nórdica estão se dedicando a esse trabalho.

\footnotetext{
${ }^{4}$ As informações sobre a coleção podem ser consultadas em: https://findingaids.lib.msu.edu/repositories/4/resources/6429

${ }^{5}$ Ver: https://norman.hrc.utexas.edu/fasearch/finding Aid.cfm?eadid=00629
} 
M: How Borges Wrote é uma pesquisa genética em todos os sentidos: analisa Borges como leitor, seus esboços, cadernos, as variantes entre manuscritos, as cópias. Tive a impressão de que sobressaem, na sua análise, as variantes, mostrando o quanto a própria forma de escrever de Borges evidencia sua "poética da incerteza, da incompletude, da possibilidade", como você escreve na introdução. Como lidou justamente com a incompletude? Como foi dar um ponto final ao livro?

DB: De fato, tinha medo de nunca terminar esse projeto, então precisei publicá-lo para ver o que acontecia depois. A estratégia que adotei de trabalhar com as notas de leitura de Borges, seus rascunhos, cadernos, variantes, versões reescritas de textos publicados, ou seja, temas clássicos da crítica genética, implicava que o livro não fosse um estudo cronológico dos manuscritos existentes e implicava que eu não tentasse imaginar o corpus total. O livro é um estudo, então, de somente parte do material que tenho agora. $\mathrm{Na}$ página do Borges Center, a nova seção intitulada "Manuscripts" mostra a lista dos manuscritos que consultei para o livro publicado em 2018 em contraste com a lista dos manuscritos consultados para a versão em espanhol, que sairá em breve na Argentina, onde pude inserir descobertas posteriores. E estou preparando uma coleção de ensaios intitulada Lo marginal es lo más bello: Borges en sus manuscritos, com escritos meus posteriores ao livro, para o final do ano.

\section{M: Houve alguma ocasião em que a pesquisa genética o fez mudar de opinião em relação ao que} pensava antes sobre a poética de Borges?

DB: O estudo genético abriu janelas. Por exemplo, em Out of context, meu livro de 1993, havia escrito um capítulo sobre "El hombre en el umbral" (1952), conto de Borges que se passa na Índia. Em 2012, tive de escrever outro ensaio sobre esse mesmo conto, intitulado "Liminares: sobre el manuscrito de 'El hombre en el

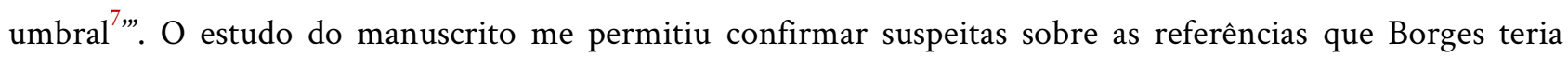
usado, mas sobretudo notar detalhes que desconhecia. Havia um verso de Kipling interpolado no conto, uma referência a um livro de Edward Lane, o tradutor de As mil e uma noites... Mas a grande descoberta propiciada pela crítica genética foi, aos poucos, desmonumentalizar Borges. A obra de Borges é um dos grandes monumentos da língua espanhola do século XX e muitos pensavam que havia ali uma espécie de perfeição absoluta. Mas Borges não acreditava na perfeição. Ao estudar os manuscritos, vemos que no processo de escrita e reescrita ele molda aos poucos suas frases, pensa em muitas opções. Vejamos, por exemplo, o ensaio "La muralla y los libros" (1950), que abre o livro Otras inquisiciones. O final, muito célebre - "esta inminencia de una revelación, que no se produce, es, quizá, el hecho estético" - foi intensamente reescrito. Essa definição do fato estético toma meia página do manuscrito, pois Borges pensa em várias alternativas antes de chegar a ela. No final do manuscrito de "El fin", conto de 1953, Borges escreve "Buenos Aires", põe a data e, mais abaixo, na mesma folha, escreve: "la inminencia de uma revelación que no se produce". A ideia de fazer alusão

\footnotetext{
${ }^{6}$ https://www.borges.pitt.edu/manuscripts

${ }^{7}$ BALDERSTON, Daniel. "Liminares: sobre el manuscrito de 'El hombre en el umbral", Hispamérica, 41, n ${ }^{\circ} 122$, agosto 2012, pp. 27-36.
} 
à definição do fato estético que havia escrito em um ensaio publicado três anos antes é tardia no processo. Borges está fazendo conexões.

M: Parece que o estudo genético mostra que nenhuma das duas imagens paradoxais, mas que são comumente atribuídas a Borges, é definitiva: a do autor como um grande erudito, versado em muitas línguas e culturas, e a do compilador de fatos de enciclopédias e livros de vulgarização... Ambas as características estão ali, não?

DB: Acho que Borges era um erudito, sim, mas um erudito relativamente pobre. Após os anos em que viveu na Europa, não saiu da Argentina e do Uruguai entre 1924 e 1961, período principal de escrita. Trabalhava com os livros a que tinha acesso, em bibliotecas e através de amigos, ou com livros que simplesmente imaginava a partir de alguma referência. Ele não necessariamente usava as melhores edições e não era um grande colecionador, tinha vários livros de coleções populares, baratas. Trata-se de uma erudição incrível, mas muito parcial e bem imaginativa. Por exemplo, no ensaio "La creación en P.H. Gosse" (1941), também de Otras inquisiciones, Borges escreve sobre as ideias de um cientista cristão da época de Charles Darwin, que tenta conciliar a existência de fósseis com o princípio de que Deus teria criado o mundo em seis dias, como está na Bíblia. Gosse conclui, no livro Omphalos: an Attempt to Untie the Geological Knot (1857), que Deus cria o mundo de fato em seis dias, mas o cria já velho. Hoje esse livro é um bestseller, pois foi recuperado pelos criacionistas, que defendem essa hipótese, mas Borges nunca teve acesso a ele. Mesmo sem ler o livro, com base apenas em referências que encontrou na Enciclopédia Britânica e na biografia escrita pelo filho de Gosse, o escritor Philip Gosse, Borges escreve todo um ensaio sobre o tema. Isso pode ser verificado nos cadernos de Borges, que permitiram à minha equipe identificar as edições que ele consultou por meio dos números de páginas escritos por ele. Fazemos um trabalho enorme de reconstrução.

\section{M: Em que está trabalhado neste momento?}

DB: Fiz uma palestra recentemente sobre um manuscrito poético de Borges que chegou até mim de forma um tanto misteriosa. Trata-se de um poema sobre seu bisavô militar, o coronel Manuel Isidoro Suárez, que lutou na batalha de Junín em 1824. Um advogado argentino, que mora na Espanha, me enviou os rascunhos dos documentos do divórcio entre Borges e sua primeira mulher, Elsa Astete Millán. Ele havia trabalhado, nos anos 1970, com outro advogado que havia aconselhado Borges em sua separação. No meio dos rascunhos para o divórcio, encontramos esse poema. Em julho, farei uma intervenção no Congresso internacional de literatura ibero-americana, e falarei sobre quatro versões de um texto em prosa, "Delia Elena San Marco", que está em El hacedor (1960). É um texto interessante, porque tem algumas versões manuscritas e uma cópia datilografada. Há poucos textos datilografados de Borges, que não sabia escrever a máquina. Quando é possível comparar versões manuscritas com versões datilografadas e versões publicadas, o dossiê genético é mais completo. 
M: Você afirma que Borges tinha o hábito de copiar os próprios poemas a mão para dar de presente a amigos ou para enviar aos editores. Como se dava essa prática?

DB: De fato, há muitos textos copiados a mão e raramente há cópias totalmente limpas, pois Borges continuava reescrevendo-os a cada versão. O poema ultraísta "Rusia", um dos primeiros escritos de Borges, tem três ou quatro cópias manuscritas, o que mostra que de fato era um hábito. Em um artigo recente $^{8}$, analiso cópias manuscritas de contos que integram o livro El jardín de senderos que se bifurcan (1941). Borges escreveu as primeiras versões desses contos, que foram publicados em revistas, no caos habitual de seus manuscritos, e, mais tarde, para editá-los no livro, copiou-os em um caderno de contabilidade. Trata-se de versões posteriores às primeiras publicações, mas que também não são versões finais. No caderno de contabilidade, então, copiou essas versões semifinais nas páginas de saldos credores. Já as páginas de saldos devedores estão em branco (risos). Esse dado é maravilhoso, pois mostra que Borges jogava um jogo consigo mesmo. Ele rasgou várias folhas do caderno, que estava em total desordem, e tive de reconstruí-lo guiando-me pelos números da contabilidade. Nesse artigo, discuto especialmente "Examen de la obra de Herbert Quain", observando as trifurcações operadas por Borges nessa versão do conto.

\section{M: É possível fazer uma boa pesquisa de arquivo somente em formato digital? A seu ver, há algo na materialidade do manuscrito que se perde na digitalização?}

DB: É sempre melhor trabalhar com originais, mas no caso de Borges, que tem um arquivo completamente disperso, não é fácil. Até pouco tempo, havia escassas edições facsimilares de manuscritos de Borges, mas hoje os pesquisadores têm diversas possibilidades. A equipe do Borges Center publicou três livros, Poemas $\mathcal{E}$ prosas breves, Ensayos e Cuentos, com muitas reproduções de boa qualidade. Em How Borges Wrote, a equipe de design gráfico fez um esforço de reproduzir detalhes dos manuscritos, para que os pesquisadores possam enxergar a gênese em seus pormenores. Então, atualmente, é possível trabalhar sem ver os originais. São boas soluções.

M: A forma caótica, como você disse, de Borges dispor seus manuscritos, escrevendo em versos de folhas antigas, em cadernos de contabilidade, também impõe um desafio aos pesquisadores. Afinal, esses suportes também são passíveis de interpretação...

DB: De fato, isto é muito interessante nos manuscritos de Borges: eles estão cheios de justaposições. Um exemplo é o manuscrito que contém o célebre ensaio "Flaubert y su destino ejemplar" (1954): na mesma folha, está escrita parte do poema "Milonga de Jacinto Chiclana", de 1965, na caligrafia da mãe de Borges. Quando havia urgência de editar um poema, na época em que estava cego, quem estava perto de Borges pegava o primeiro papel que estivesse à mão (risos). Ele não tinha grande fetiche pelos manuscritos. $\mathrm{O}$ escritor Manuel Mujica Láinez doou uma coleção de manuscritos de vários autores à Biblioteca Nacional argentina na época em que Borges era diretor. Nas entrevistas aos jornalistas, Borges fez piadas,

\footnotetext{
${ }^{8}$ BALDERSTON, Daniel. "Las páginas del Haber en un cuaderno de contabilidad, marca Caravela: las copias en limpio de los cuentos de Borges de 1939 a 1941”, La Palabra, 38, setembro de 2020, p. 21-31.
} 
minimizando a importância que teriam esses manuscritos dos séculos XIX e XX. Seus próprios manuscritos foram espalhados em vida: Borges nunca se preocupou em guardá-los ou organizá-los.

M: Isso é curioso, dado que o próprio Borges era um autor que valorizava o processo, que escreveu que "só o cansaço" é que faz dar-se um texto por terminado...

DB: Talvez por isso mesmo ele quisesse espalhar o material. Que escolhesse deixá-los nas redações dos jornais, das revistas, largá-los nas editoras, dá-los de presente a amigos, esquecê-los em diversos lugares... Não tinha medida do valor dos manuscritos, ao menos dizia que não tinha (risos).

M: Ou era justamente uma forma de impedir que se constituísse um acervo com seus manuscritos (risos)...

DB: O problema é que agora muitos manuscritos de Borges estão nas mãos de colecionadores particulares e atingem preços absurdos, tornando-se inacessíveis aos pesquisadores. Trabalhei recentemente com o manuscrito de um ensaio, "Cuentos del Turquestán", publicado no jornal La Prensa em 1926. É um texto quase desconhecido e, segundo os documentos de leilão, foi vendido na França por 10.400 euros, não se sabe para quem. A Fondation Martin Bodmer, uma instituição suíça, comprou recentemente dois manuscritos de Borges por 300.000 euros. E pensar no pouco valor que Borges atribuía a seus papéis...

M: Você observa que Borges mudou sua grafia ao menos quatro vezes. Para além da questão física, da progressiva cegueira, como podemos interpretar essas transformações?

DB: Borges experimentou em 1919, 1920 e 1921 uma caligrafia muito artificial, de influência expressionista, como as usadas em cartazes de cinema. Era uma homenagem clara ao expressionismo alemão, que ele apreciava. Em 1922, essa letra desaparece e o que prevalece é uma caligrafia muito pequena - como a "letra de inseto" de Pierre Menard, o personagem de "Pierre Menard, autor del Quijote" (1939). Porém, simultaneamente a essa "letra de inseto", surge uma letra maior, mais legível. Alguns pesquisadores pensavam que isso representava uma mudança cronológica de sua caligrafia, mas descobrimos que se tratava de um sistema diferente para a composição e para a cópia: a letra menor era usada para a composição, a maior para as cópias passadas a limpo em papel quadriculado. A quarta letra que menciono em How Borges Wrote, no entanto, é a letra com que Borges escreve quando já está cego, e que usa sobretudo para assinar documentos e livros para amigos e colecionadores.

M: Ricardo Piglia, de quem você foi próximo, foi um reescritor contumaz, como Borges. Retornou constantemente aos seus escritos, propondo novas edições, inclusões e exclusões de contos e até modificando narrativas de uma edição para outra. Os três volumes dos Diários de Emilio Renzi (20152017) reforçam essa característica do autor reescritor. O que sua visão geral dos cadernos de Piglia, que 
estão conservados na Firestone Library, na Princeton University, revelam sobre a composição dos Diários?

DB: Fui três vezes aos arquivos de Ricardo Piglia, mas não fiz um trabalho sistemático, ao contrário de outros pesquisadores. Entretanto, o que fica claro nos cadernos que deram origem aos Diários de Emilio Renzi é que o autor revisita essas anotações muitas vezes na vida. Nas últimas folhas dos cadernos, ou em folhas que estão no início, há marcas de seleção de Piglia antes de ficar doente, já pensando em versões para a publicação. Os cadernos se iniciam antes do marco inicial dado por Piglia na versão publicada: não aos 16 anos, ao se mudar de Adrogué a Mar del Plata, e sim aos 13 anos, e assinando como Ricardo Emilio Piglia Renzi. Agora estou trabalhando com os cadernos de Borges, então não vou me permitir uma distração grande com os papéis de Ricardo. Meu último livro, Leído primero y escrito después: aproximaciones a las obras de Roa Bastos, Piglia y Saer (Editorial Universitaria Villa Maria, 2020), tem alguns ensaios genéticos, sobretudo no que concerne à composição do romance Plata Quemada (1997) e à relação com o maoísmo argentino. Mas foram escritos em diferentes ocasiões. O estudo genético desse imenso arquivo de Piglia ainda está para ser feito.

\section{M: Que lugar a crítica genética ocupa atualmente entre os estudos literários nos Estados Unidos?}

DB: Não é uma tendência forte no mundo anglófono em geral. Não temos uma revista como a Manuscrítica, apenas iniciativas esparsas. Nos Estados Unidos há a tradição da Textual Scholarship, que às vezes interage com a crítica genética, mas possui convenções de transcrição muito diferentes. Há trabalhos importantes sobre a gênese de obras de autores de língua inglesa, como James Joyce, Samuel Beckett e Emily Dickinson. Entre eles, The Gorgeous Nothings (2012), uma grande edição facsimilar dos poemas de Emily Dickinson, e Text as process: Creative Composition in Wordsworth, Tennyson, and Dickinson (2009), de Sally Bushell. Mas os Estados Unidos têm importantes acervos de escritores, inclusive muitos hispano-americanos, a serem explorados.

Recebido em: 22 de junho de 2021 